\title{
Myeloid Lineage of Human Endothelial Outgrowth Cells Circulating in Blood and Vasculogenic Endothelial-Like Cells in the Diseased Vessel Wall
}

\author{
Chunsheng Liu ${ }^{a}$ Shaohua Wang ${ }^{a}$ Pat Metharom ${ }^{b}$ Noel M. Caplice ${ }^{b}$ \\ a Division of Cardiovascular Diseases and Molecular Medicine Program, Mayo Clinic, Rochester, Minn., USA; \\ ${ }^{b}$ Centre for Research in Vascular Biology, BioSciences Institute, University College, Cork, Ireland
}

\section{Key Words}

Endothelial progenitors - Myeloid lineage cells .

Microvasculature $\cdot$ Monocytes $\cdot$ Vascular injury

\begin{abstract}
Endothelial injury is a major step in the pathogenesis of atherosclerosis. Accumulated data suggest endothelial progenitor cells can derive from various sources, including the host bone marrow, circulating blood mononuclear cells, as well as resident precursors within the vessel wall. Early experimental animal data supported a haematopoietic origin for vascular precursors, but more recently cells of myeloid lineage have been suggested as precursors of endothelial and smooth muscle cells. However, to date, little evidence exists to support a myeloid lineage-endothelial cell differentiation pathway within the vasculature of human subjects. Here, we undertook two sets of experiments aimed at determining whether (a) blood endothelial outgrowth cells (EOC) had a myeloid lineage and whether (b) chimeric endothelial-like cells within the neovasculature of gender-mismatched cardiac transplant arteriopathy subjects shared common myelomonocytic markers. We show here that in vitro bloodderived EOC and recipient-derived endothelial-like cells participating in vasculogenesis in vivo share some myeloid immunophenotypes. Additionally, these microvascular chimeric cells show no evidence of tetraploidy or cell fusion.
\end{abstract}

Copyright $\odot 2009$ S. Karger AG, Basel

\section{Introduction}

Endothelial injury is a major step in the pathogenesis of atherosclerosis. Accumulated data suggest endothelial progenitor cells (EPC) can derive from the host bone marrow, circulating blood mononuclear cells (MNC), as well as resident precursors within the vessel wall [1-7]. It is accepted that re-endothelialisation and restoration of function of denuded or injured vasculature is contributed to some degree by circulating EPC. Severe vessel injury has been shown to augment circulating EPC numbers significantly, suggesting EPC mobilisation is part of the response to vascular damage. EPC can be cultured from many, although not necessarily separate, cell populations such as lineage-negative c-kit-positive bone marrow (BM) cells [5], CD34+ cells and monocytes from blood [2, 4], nonmonocytic CD14- blood MNC [8] and side population cells isolated from $\mathrm{BM}$ and peripheral tissues [6]. Recently, De Palma et al. [9] showed that, at least in a tumour model, it is the lineage of pro-angiogenic monocytes, a Tie-2-expressing subset, that is responsible for vascularisation, and not BM-derived EPC. However, in another experiment, Tie-2-expressing cells were recruited during thrombus recanalisation, but did not line the new vessels [10]. These seemingly contradictory differentiation and functional paths suggest that EPC can indeed arise from a variety of sources if the circumstances require it. The diverse physiological response due to differ-

Dr. Noel M. Caplice

Centre for Research in Vascular Biology

BioSciences Institute, University College

Cork (Ireland)

Tel. +353 214901 326, Fax +353 214901 446, E-Mail n.caplice@ucc.ie 
ent intensity and mode of injury is likely to create a multitude of microenvironments, recruiting and activating a range of cell types, some of which may be highly adaptive (plasticity) and act as endothelial-like cells when resident endothelial cells (EC) are depleted or injured. Although early experimental animal data supported a haematopoietic origin for vascular precursors, more recently cells of myeloid lineage have been suggested as precursors of endothelial and smooth muscle cells [11-13]. Since these cells are found in abundance in the peripheral circulation, the clinical implication of vascular cell differentiation from such cells is tremendous. However, to date, little evidence exists to support a myeloid lineage-EC differentiation pathway within the vasculature of human subjects.

We have recently shown that in vitro smooth muscle outgrowth cells (SOC) can grow from peripheral MNC and appear to be of myeloid lineage [14]. Also, smooth muscle cells exhibiting some myeloid phenotypic characteristics were detected within the microvasculature of atherosclerotic vessels. Using the same experimental design, we undertook two sets of experiments aimed at determining (a) whether blood endothelial outgrowth cells (EOC) had a myeloid lineage and (b) whether chimeric endothelial-like cells within the neovasculature of gender-mismatched cardiac transplant arteriopathy subjects shared common myelomonocytic markers. We show here that in vitro blood-derived EOC and recipient-derived endothelial-like cells participating in vasculogenesis in vivo share some myeloid immunophenotypes. Additionally, these microvascular chimeric cells show no evidence of tetraploidy or cell fusion.

\section{Patients and Methods}

\section{Patients and Autopsy Tissue}

Coronary artery specimens used in the studies were from 5 males who had received a gender-mismatched cardiac transplant. Healthy volunteer blood donors $(n=20)$ were used to study EOC. The institutional review board at the Mayo Clinic approved the use of all autopsy specimens and donor blood. All transplant patients gave consent before surgery for their tissue to be used in research studies.

\section{MNC Isolation, EOC and SOC Culture}

MNC were isolated from healthy blood donor buffy coats as previously described [15]. Freshly isolated MNC were seeded in 12-well plates coated with collagen type I and cultured in EGM-2 medium. Three weeks later, EOC were expanded from colonies and maintained in EGM-2 medium. EOC used for all experiments were restricted to passages 4-6. Human coronary artery EC (HAEC) were obtained from Clonetics. Both HAEC and SOC were used as control cell lines for the lineage determination of EOC in reverse transcriptase polymerase chain reaction (RTPCR). SOC were cultured as previously described [14]. Briefly, peripheral blood MNC were isolated from buffy coats and cells were seeded in 12-well plates coated with collagen type I and cultured in EGM-2 medium (Cambrex) at 5 million cells per well. Three weeks later, SOC were expanded from colonies and maintained in EGM-2 supplemented with PDGF-BB (50 ng/ml, R\&D Systems).

\section{Clonogenic and Proliferative Potential Assay}

To examine the clonogenic capacity and proliferative potential of EOC, a previously described single-cell deposition assay [14] was utilised in this study. Early passages of initial outgrowth of EOC were seeded into 96-well plates at a density of 0.3 cells/well in EGM-2 medium. Individual wells were examined under a contrast microscope to ensure that only one single cell was placed into each well. Medium was changed every 3 days and after 2 weeks, and each well was examined for outgrowth. This outgrowth was designated as primary colonies. Additionally, cells derived from primary clones were further employed in a single-cell deposition assay, resulting in clones which were designated as secondary colonies. Tertiary colonies were likewise derived from secondary clones. In parallel, early-passage EOC were transduced with a GFP-expressing lentiviral vector pHR'SIN-CSGW provided by Dr. A. Thrasher (Institute of Child Heath, London, UK). The packaging (pCMVR8.91) and VSV-G (pMDG) plasmids were used together with pHRSIN-CSGW to make viral vectors by cotransfection in $293 \mathrm{~T}$ cells. Two days after transfection, the culture supernatants were harvested and passed through a filter $(0.45 \mu \mathrm{m}$ pore size).

Lentiviral GFP-transduced single cells were identified by positive immunofluorescence. Medium was changed every 3 days and after 2 weeks, and each well was examined for colony growth. Colonies were graded after 14 days of culture according to size into various categories: $2-50,50-200,200-2,000,2,000-10,000$ and $>10,000$ cells. The colonies with $>2,000$ cells were expanded into 24-well plate and further expanded into T-75- $\mathrm{cm}^{2}$ flasks for long-term culture.

Antibodies and Lineage-Specific Markers

The following specific antibodies and mRNA expression markers were used for lineage determination by FACS, in situ immunofluorescence staining and PCR: eNOS, Tie-2, CD31 and VE-cadherin (VECAD) for EC lineage; CD14, CD68 and Mac-1 for myeloid lineage, and CD34, Flk-1 and CD45 for angioblastic and haematopoietic lineage. The primers used for the determination of mRNA expression profiles in EOC, SOC and HAEC are shown in table 1 . The primary antibodies used were mouse monoclonal antibodies against Mac-1 (CD11b, Ancell, 159-020), CD31 (Dako, M0823), CD34-PerCP (for FACS, BD Pharmingen, BDEurope, 345804), CD34 (for immunofluorescence, Santa Cruz, sc-7324), Flk-1 (Santa Cruz, sc-6251), CD45 (Santa Cruz, sc-1178), rabbit polyclonal antibodies against CD68 (Santa Cruz, sc-9139), Tie-2 (Santa Cruz, sc-324) and goat polyclonal antibodies against CD14 (Santa Cruz, sc-6997). Cy3-conjugated goat anti-mouse (Chemicon, 21071069), goat anti-rabbit (Chemicon, 21082328), Alexa Fluor 488-conjugated goat anti-mouse (Molecular Probes, A11001) and goat anti-rabbit (Molecular Probes, A11008), fluorescein isothiocyanate (FITC)-conjugated rabbit anti-goat polyclonal anti- 
Table 1. Primers and PCR conditions for EOC phenotyping

\begin{tabular}{|c|c|c|c|c|}
\hline Primer & & Sequence & $\begin{array}{l}\text { Product } \\
\text { size, bp }\end{array}$ & $\begin{array}{l}\text { Annealing } \\
\text { temperature, }{ }^{\circ} \mathrm{C}\end{array}$ \\
\hline eNOS & $\begin{array}{l}5^{\prime} \\
3^{\prime}\end{array}$ & $\begin{array}{l}\text { 5'-GGT ATG GAT GAG TAT GAC GTG-3' } \\
5^{\prime} \text {-TGT TCC GGC CGA GGG-3' }\end{array}$ & 171 & 51 \\
\hline VECAD & $\begin{array}{l}5^{\prime} \\
3^{\prime}\end{array}$ & $\begin{array}{l}5^{\prime} \text {-AAC TTC CCC TTC TTC ACC C-3' } \\
5^{\prime} \text {-AAA GGC TGC TGG AAA ATG-3' }\end{array}$ & 368 & 51 \\
\hline Tie-2 & $\begin{array}{l}5^{\prime} \\
3^{\prime} \\
3^{\prime}\end{array}$ & $\begin{array}{l}\text { 5'-TTC CAA CAT TAC ACA CTC C-3' } \\
\text { 5'-GCT ATA AGC AGC ATC TTC C-3' } \\
5^{\prime} \text {-ATC ATT CCT GTG GGC TTT TTG TG-3' }\end{array}$ & 291 & 48 \\
\hline G3PDH & $\begin{array}{l}5^{\prime} \\
3^{\prime}\end{array}$ & $\begin{array}{l}5^{\prime} \text {-CCA TGT TCG TCA TGG GTG TGA ACC A-3' } \\
5^{\prime} \text {-GCC AGT AGA GGC AGG GAT GAT GTT C-3' }\end{array}$ & 251 & 59.9 \\
\hline
\end{tabular}

bodies (DAKO, F0250) were used as secondary antibodies for unconjugated primary antibodies. For all immunophenotyping experiments, an isotype-matched mouse, rabbit or goat IgG control was used at the same time to exclude nonspecific detection.

\section{Immunohistochemical Analysis of Cultured Cells}

Cultured cells were seeded in 8-well Chamber Slide systems overnight to achieve $60 \%$ confluence. The slides were fixed in $4 \%$ paraformaldehyde at $37^{\circ} \mathrm{C}$ for $10 \mathrm{~min}$ and blocked for $45 \mathrm{~min}$ at room temperature with $10 \%$ normal goat serum. After decanting off the blocking solution, the slides were incubated with primary antibodies at $37^{\circ} \mathrm{C}$ for 30 min and washed with PBS; then secondary antibodies were added and incubated at $37^{\circ} \mathrm{C}$ for $30 \mathrm{~min}$. The blocking serum, primary and secondary antibodies for eNOS, Tie-2, Flk-1 and CD68, were made up in 0.2\% Triton X-100 PBS solution. After washing twice with PBS, the slides were stained with 4',6-diamidino-2-phenylindole (DAPI) and analyzed using confocal microscopy.

\section{FACS Analysis}

The expression of cell lineage-specific markers was also analyzed by FACS using surface and intracellular antigen immunolabelling protocols. Cultured EOC were lifted with Versene EDTA and washed in PBS. For intracellular antigen identification, cells were fixed with $0.02 \%$ paraformaldehyde and then permeabilised in $0.2 \%$ Tween-20 solution. For surface antigen detection, cells were resuspended in PBS supplemented with 1\% BSA. Subsequently, cells were incubated with a series of primary antibodies on ice for $30 \mathrm{~min}$, washed twice and then detected with FITCconjugated secondary antibodies applied in the same way. Cells were again washed and fixed in $1 \%$ paraformaldehyde for surface antigen detection or in buffer (PBS supplemented with 2\% FBS) for intracellular antigen detection as previously described [15] for FACS analysis.

\section{$R T-P C R$}

RT-PCR was performed for the detection of lineage-specific mRNA expression. Cultured human EOC, SOC and HAEC were collected and washed with PBS; total RNA was extracted using the RNeasy Midi kit according to the manufacturer's instructions
(Qiagen). Reverse transcription was performed for cDNA synthesis with an RT-PCR kit (Invitrogen, 1175813) with $5 \mu \mathrm{g}$ of total RNA per sample. The cDNA products were stored at $-20^{\circ} \mathrm{C}$ until used. For RT product amplification, a PCR reagent system kit (Invitrogen) was used. Following the manufacturer's protocol, $2 \mu \mathrm{l}$ of RT product were added to $50 \mu$ l of reaction system per sample; the mixtures were subsequently denatured at $94^{\circ} \mathrm{C}$ for $4 \mathrm{~min}$, amplified at $94^{\circ} \mathrm{C}$ for $30 \mathrm{~s}$, annealed at the temperatures indicated in table 1 for $30 \mathrm{~s}$ and extended at $72^{\circ} \mathrm{C}$ for $90 \mathrm{~s}$ for 35 cycles using a T-gradient PCR machine. PCR products were electrophoresed in $1 \%$ agarose gels at $120 \mathrm{~V}$ for $90 \mathrm{~min}$ and visualised on an UV transilluminator. Oligo primers used are shown in table 1.

\section{Immunohistochemical Analysis and Fluorescent in situ \\ Hybridization (FISH)}

Formalin-fixed, paraffin-embedded sections were deparaffinised using CitriSolv (Fisher Scientific) and rehydrated in 100, 95, 85 and $75 \%$ ethanol solutions to PBS. Immunohistochemical analysis was performed using antibodies against Tie-2, CD31, CD34, Flk-1 and CD68, as previously described $[12,15]$. In certain cases after immunostaining, FISH for Y chromosome detection was immediately performed. The tissue was dehydrated twice in $100 \%$ ethanol for $1-2 \mathrm{~min}$ and then heated in a steamer in preheated $1 \mathrm{mM}$ EDTA (pH 8.0) for $10 \mathrm{~min}$, followed by $0.4 \%$ pepsin A $(2,100$ units $/ \mathrm{mg})$ in buffer $(0.9 \% \mathrm{NaCl})$ at $37^{\circ} \mathrm{C}$ for $10 \mathrm{~min}$. The tissue was then rinsed in an ethanol series from 75,85 to $100 \%$. Subsequently, the hybridization probe cocktail (Vysis, 30-804824) was applied to the sections. The DNA probe used was specific for the $\alpha$-satellite region of the Y chromosome and was fluorescently labelled (FITC-green, CEPY, Vysis, B-6927). For combined immunostaining and FISH, Tie-2-Alexa Fluor (green) and CD68Cy3 (red) staining with Y chromosome FITC labelling were used. Coverslips were affixed and sealed with rubber cement, and the slides were incubated at $80^{\circ} \mathrm{C}$ for 3 min to denature DNA and then incubated at $37^{\circ} \mathrm{C}$ overnight. After hybridization, the slides were washed in $2 \times \mathrm{SSC} / 0.1 \% \mathrm{NP}-40$ solution at room temperature, counterstained with $0.03 \mu \mathrm{g} / \mathrm{ml}$ DAPI and mounted with Vectashield (Vector Laboratories, H-1200). FISH signals were enumerated using a Zeiss Axioplan microscope equipped with a triplepass filter (Vysis). 
Analysis of Cell Fusion Using FISH Sex Chromosome Analysis

To examine cell fusion in chimeric endothelial and smooth muscle-like cells within the vessel wall, sex chromosome ploidy analysis was performed in combination with immunohistochemistry for myeloid (CD68)- and endothelial (Tie-2)-specific markers. Chimeric cells were analyzed using a triple-pass filter which allowed clear delineation of FISH and immunohistochemical signals. Three-dimensional cell reconstruction was performed on confocal microscopy to ensure correct coregistration of FISH signals with surrounding cytoplasmic staining.

\section{Data and Statistical Analysis}

Each section was reviewed by two experienced observers blinded to the sex of the donor and recipient. Sections were reviewed on the same microscope to ensure the image was consistent and reproducible. Only sections that contained a clear morphology with adequate immunohistochemical and FISH staining were considered for analysis. Cells positive for Tie-2 or CD31 were considered of endothelial and myeloid lineage if CD68 positive. A nucleus was considered of male origin if there was a clear Y-chromosome signal (green) within a blue DAPI-stained nucleus. The quantity of dual-lineage (myeloid- plus endothelial marker-positive) cells were determined by double immunostaining and confirmed by FISH detection of recipient chimeric Y chromosome in these cells. The numbers of double-lineage and chimeric cells from each subject were averaged and expressed as percentages $( \pm$ $\mathrm{SD})$ of the total CD68-positive cell counts within the intima and adventitia of these vascular regions. A total 25,000 nuclei were analyzed in a blinded fashion, approximating 5,000 nuclei per sex-mismatched subject $(\mathrm{n}=5)$.

\section{Results}

\section{Lineage of EPC Colonies}

Clonally expanded colonies exhibiting an endothelialand smooth muscle-specific phenotype were grown out from peripheral blood MNC and differentially expressed vascular cell-specific proteins and mRNA (fig. 1). High expression of Tie-2 receptor, eNOS and VECAD distinguished EOC from initial MNC populations where all of these markers were negligible or absent. Messenger RNAs for Tie-2, eNOS and VECAD were all detected in EOC and a positive control EC line, HAEC, but not in MNCderived SOC (fig. 1). Flow cytometry showed EOC to be strongly immunoreactive for myeloid markers CD68 and Mac-1 (CD11b) with lower expression of CD14 (fig. 1). Leukocyte marker CD45, positive on MNC (data not shown), and stem cell marker CD34 were negative on EOC. Subsequent passage of EOC colonies, from a singlecell deposit, revealed endothelial markers eNOS, VECAD, Tie-2 and angioblastic marker VEGF-R2, and myeloid markers CD68 and Mac-1 to be still retained (fig. 2).
Growth Kinetics and Clonogenic and Proliferative Potential of Secondary and Tertiary EOC Colonies Derived from Single-Outgrowth Primary Cells

The ability of MNC-derived EOC to form secondary and tertiary colonies with high proliferative potential (HPP), the so-called HPP-colony forming cell (HPPCFC), was assessed by seeding EOC as single cells (fig. 3ae). In approximately $30 \%$ of cases, EOC single cells gave rise to secondary colonies $>2,000$ cells in a 14-day period (fig. 3f). Figure $3 \mathrm{~g}$ and $3 \mathrm{f}$ shows growth kinetics of three different secondary clones (C1, C2 and C5) from day 14 to day 21 and population doubling times, respectively. C5, which showed the highest proliferative potential $(>10,000$-cell colony) had a population doubling time of approximately 1.5 days. Evaluating further HPP-EOC, single cells reseeded from these colonies were capable of forming tertiary HPP colonies although their ability for reproliferation markedly reduced, with only $5-10 \%$ of single cells giving rise to colonies $>2,000$ cells (fig. $3 \mathrm{i}-\mathrm{k}$ ). When secondary or tertiary colonies of HPP-EOC were immunophenotyped by FACS, there was consistently high expression of endothelial and myeloid markers eNOS, VECAD, Tie-2, CD68, Mac-1 and myeloperoxidase. Additionally, cells derived from tertiary colonies were able to form tubes in vitro on a growth factor-reduced Matrigel (online supplementary fig. 1; www. karger.com/doi/10.1159/000226226).

\section{Myeloid Cells Co-Expressing Endothelial Markers \\ Integrate into Regions of Neovascularisation within \\ Diseased Transplant Atherosclerotic Vessels}

To investigate whether precursor cells participating in vasculogenesis in vivo possessed a dual profile of endothelial-specific and myeloid antigens, arterial segments from diseased subjects who had undergone sex-mismatched cardiac transplantation were examined immunohistochemically using endothelial- and myeloid-specific antigens and FISH for Y chromosomes to distinguish recipient from donor cells. Immunostaining for the classic myeloid marker CD68 demonstrated extensive CD68-positive endoluminal cell infiltration within adventitial and intimal microvessels (fig. 4). Microvessels with integrated CD68-positive cells in the adventitia contained multiple signet-ring-shaped tubes with eccentric nuclei and cell cytoplasm encircling a hollow lumen (fig. 4b, c). These CD68-positive cells were confirmed as recipient in origin by combined FISH analysis for Ychromosome and CD68 immunofluorescence staining (fig. 3d). Double immunolabelling of CD68-positive cells lining the lumen of these microvessels also confirmed 
Fig. 1. Characterisation of EOC. FACS analysis of haematopoietic, angioblastic and myeloid markers. EOC (a) expression of monocytic markers CD68, Mac- 1 and to a lesser extent CD14, but lack of the panleukocyte marker CD45. EOC were positive for Flk1, eNOS, VECAD and Tie-2 (a). In contrast, $\mathrm{MNC}$ were negative for endothelial markers eNOS, VECAD and Tie-2 (b). c Analysis of endothelial marker transcript expression in EOC, SOC and HAEC by RT-PCR.
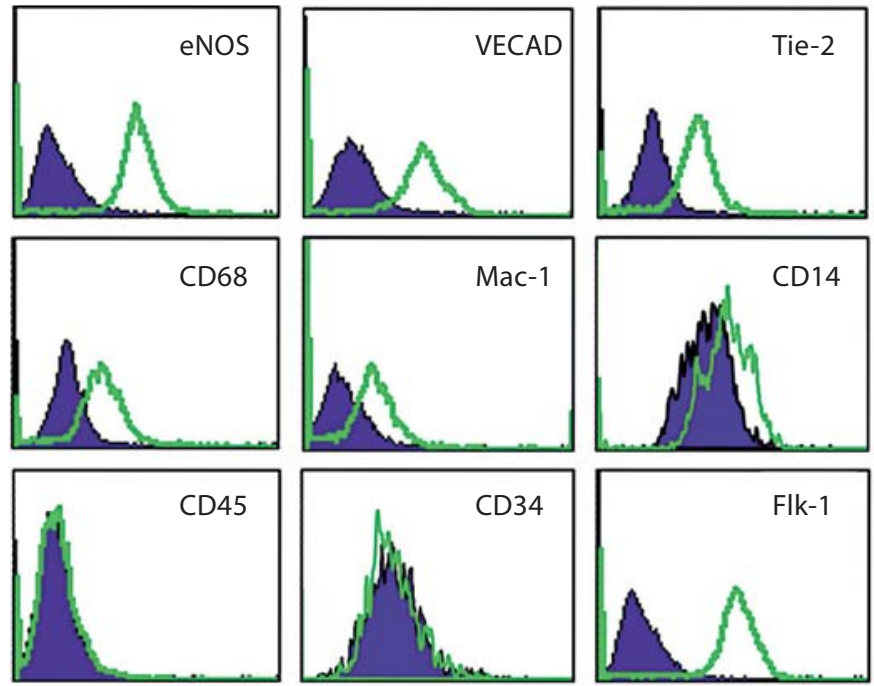

a
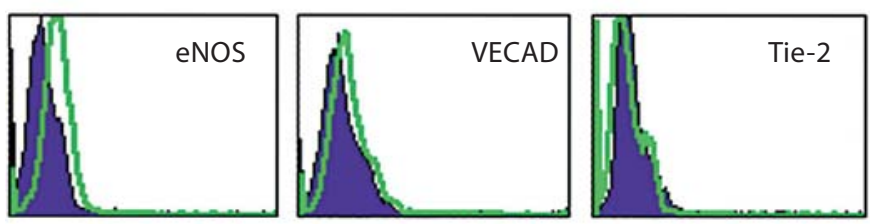

b
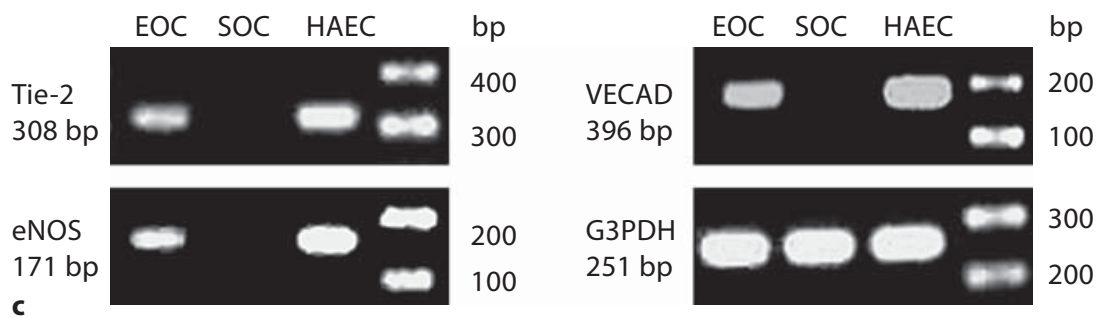

costaining of CD68 with multiple endothelial-specific antibodies to Tie-2, CD31, CD34 and Flk1 (fig. 4e-h). In figure 5, a longitudinal section with CD68 and Tie-2 double staining is shown.

\section{No Evidence for Cell Fusion in Myeloid Cells \\ Expressing Endothelial Antigens}

To test whether cell fusion accounted for myeloid lineage in cells co-expressing endothelial markers within microvessels of diseased arteries, sex-chromosomal ploidy analysis using FISH combined with dual immunolabelling for myeloid and EC antigens was performed. All CD68-positive cells that showed dual positivity for Tie-2 were confirmed to be of recipient origin by FISH for Y chromosomes, and these cells were also confirmed as diploid (>1,000 nuclei analysed) following sex-chromosomal ploidy analysis (fig. 6). These unfused cells were detected as previously described in microvessels within the adventitia and intima of plaques. Moreover, three-dimensional reconstruction of Z-plane images on confocal microscopy confirmed co-expression of Tie-2/CD68 with single $\mathrm{X}$ and $\mathrm{Y}$ chromosomes, validating the diploid nature of these cells (online suppl. movie 1). Quantitation of myeloid/endothelial double-positive cells within the adventitial microvasculature, intima and adventitial loose connective tissue of diseased coronary arteries from 5 human subjects revealed approximately $14.0,0$ and $22.5 \%$, respectively, for CD68/Tie-2 double-positive cells of the total CD68-positive cells within those regions (fig. 7). 

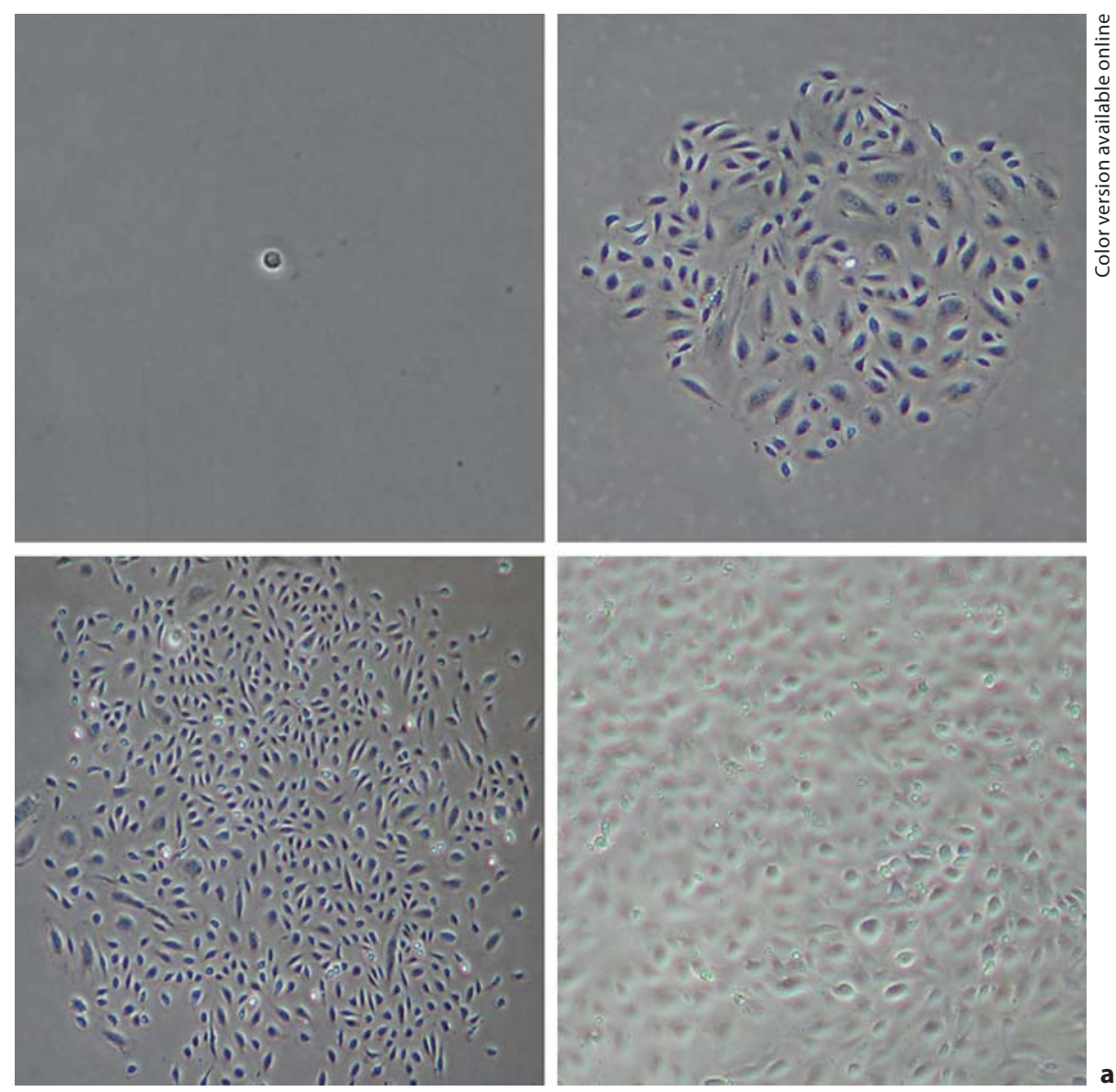

Fig. 2. a Primary outgrowth colony formation following single-cell deposition, expanding colony and confluent monolayer by phase contrast microscopy. b FACS analysis showed positivity with endothelial markers (eNOS, VECAD, Tie-2 and Flk-1) and some myeloid markers (CD68 and Mac-1). G3PDH shows equivalent RNA loading conditions.
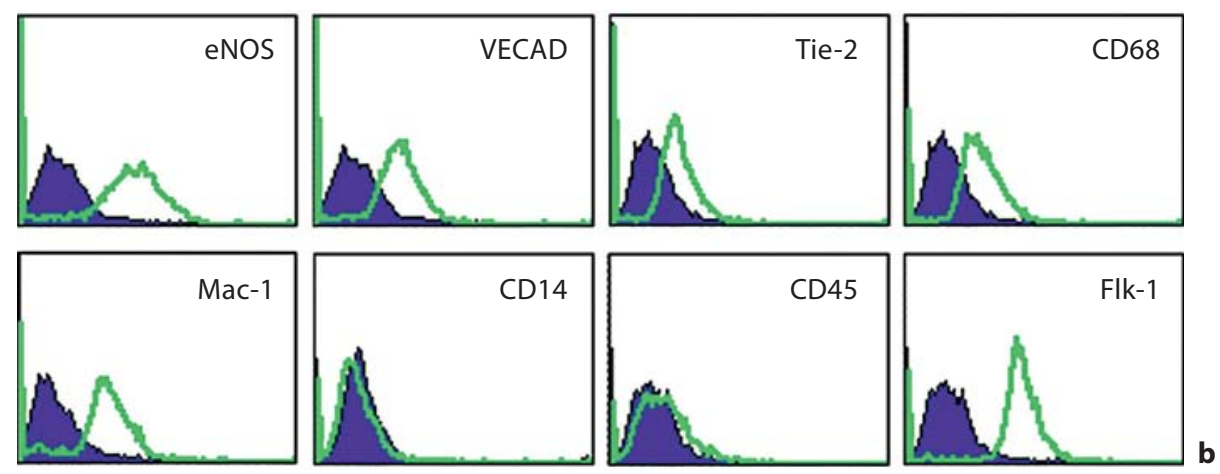

Fig. 3. Growth kinetics, clonogenic and proliferative potential of single outgrowth cells derived from EOC colonies. a-e Representative photomicrographs of different GFP-labelled EOC colonies ranging from single-cell clones (a) to clusters (b, $\mathbf{c} ; \sim 25-250$ cells) and expanded colonies (d, e; $>500$ cells). The panels on the left show phase contrast microscopy and those on the right fluorescence microscopy for intracellular GFP expression. $f$ Percentages of lowly and highly proliferative clones arising from single-cell deposits. Growth kinetics of secondary colonies from days 14 to
49 after initial single-cell seeding of three different clones (C1$\mathrm{C} 3 ; \mathbf{g})$ and population doubling time (PDT) indicating the growth kinetics of two HPP EOC (C2 and C5) and a clone with less proliferative potential $(\mathrm{C} 1 ; \mathbf{h})$. i Formation of tertiary colonies. j Percentages of lowly and highly proliferative tertiary clones from single-cell deposits. k Phenotypic analysis of tertiary clones with endothelial and myeloid markers eNOS, VECAD, Tie-2, CD68, Mac-1 and myeloperoxidase (MPO). 


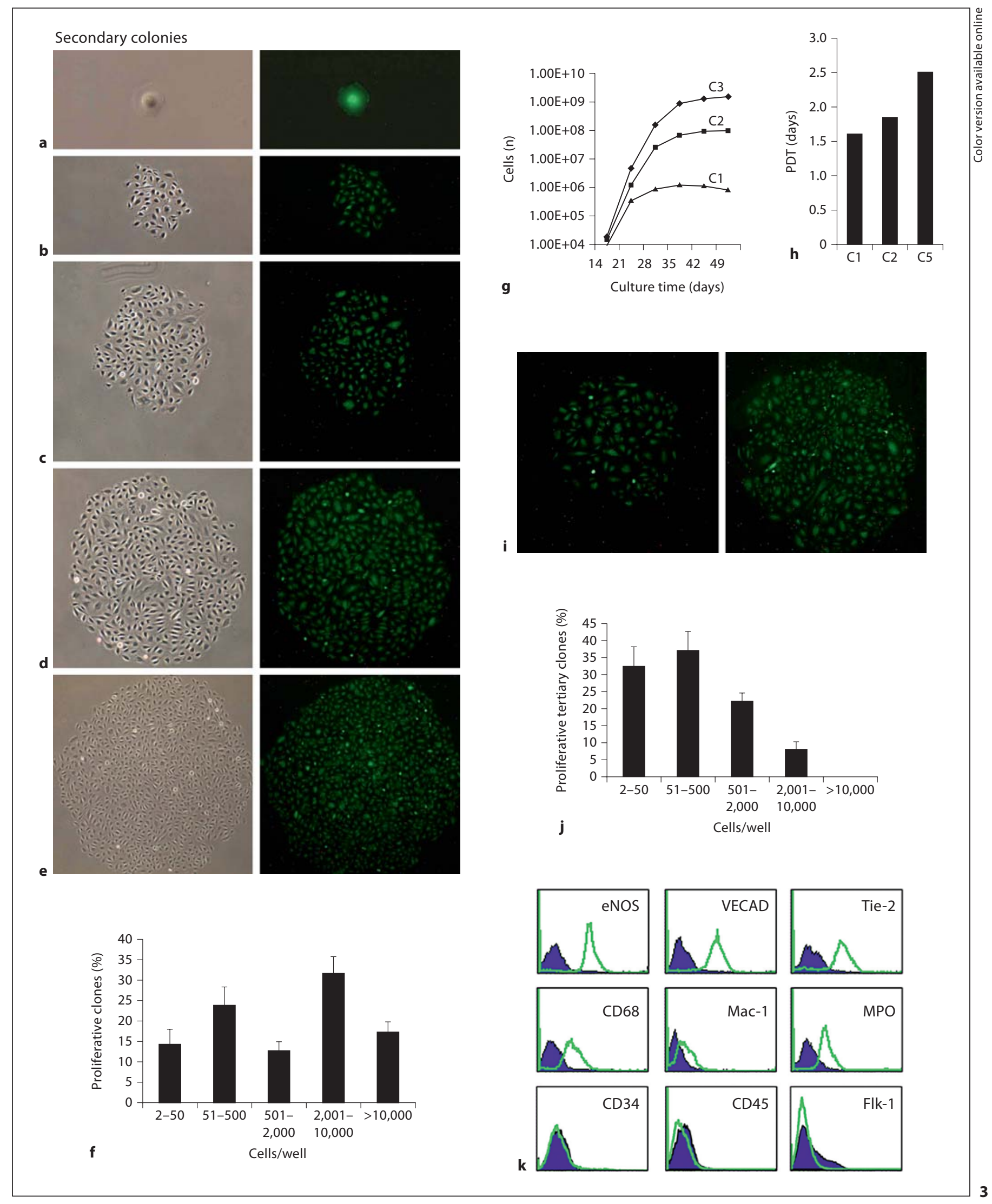



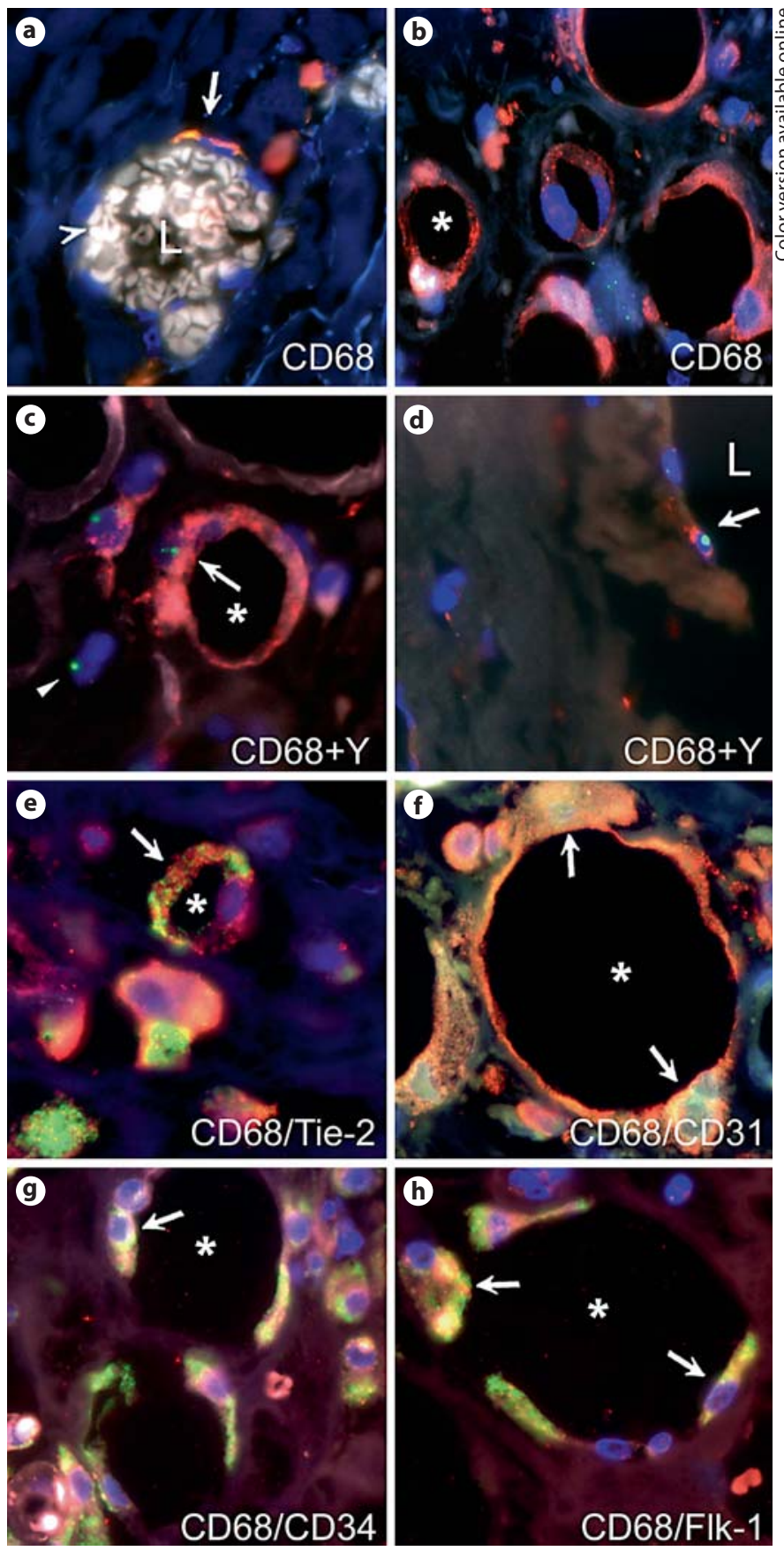

Fig. 4. Immunostaining of CD68 and costaining of CD68 with endothelial-specific antigens in microvessels within the adventitia of diseased coronary arteries (please note: colours are shown in the online version only). a Immunostaining of CD68+ cells (arrow; red) lining adventitial microvessel. Note erythrocytes (white; open arrowhead) within the microvessel lumen (L). b Multiple CD68+ cells (red) in microvessels within the adventitia of a medium-sized diseased artery. c Recipient-derived Y-chromosomepositive (green dot in blue nucleus) $\mathrm{CD} 68+$ (red) cell in adventitial microvessel (arrow) of a vasculopathic coronary artery from a pa-

\section{Discussion}

Vascular remodelling in atherosclerosis is a dynamic process involving intimal smooth muscle cell proliferation, inflammatory cell infiltration/accumulation and EC neovascularisation. Along with emerging data suggesting BM and circulating precursor cells can actively participate in intimal plaque biology and in neovascularisation [16-19], the source of vascular cells involved in remodelling are intensely investigated as possible targets for therapeutics. Focus has recently been placed on the circulating origin of EC present in the adult vasculature, particularly after injury [20-23]. In vitro studies show that endothelial-like cells can be grown in extended culture from human peripheral blood MNC [2, 24]; however, the lineage of circulating cells that may contribute EC to the neovascularised portion of atherosclerotic vessels remains unclear. This study indicates that blood EOC expanded in culture and EC-like cells contributing to microvasculature in vivo exhibit a myeloid lineage immunophenotype, suggesting that circulating myeloid cells may play a larger role in the vascular biology of atherosclerosis either, as traditionally thought, by supplying a local inflammatory cell milieu favouring vasculogenesis or directly by differentiation into endothelial-like cells.

Our single-cell deposition clonogenic assay suggests a proliferative potential for blood-derived EOC. However, unlike SOC [14], the EOC capacity to highly propagate after serial passaging seems to lessen quite noticeably with time in culture (e.g. clones with ability to form $>10,000$-cell colonies were no longer observed in expanded tertiary cultures). Phenotypic analysis of primary EOC indicated possible derivation from myeloid cells [based on CD68, CD14 and Mac-1 (CD11b) positivity], although the expression level of these markers, particularly CD14, dissipated over time, most likely an in vitro culture phenomenon. Multiple endothelial markers eNOS, VECAD

tient after gender-mismatched cardiac transplantation. Note the male cell that is not CD68+ (solid arrowhead). d Single CD68+ recipient-derived male cell at the luminal edge of atherosclerotic plaques from a male patient with transplant vasculopathy of a female donor heart. e-h Co-immunostaining (yellow) of CD68 (red) with endothelial-specific markers (green) for Tie-2 (e), CD31 (f), CD34 (g) and Flk1 (h) in adventitial microvessels of diseased coronary arteries. Arrows indicate costaining cells. Asterisks indicate the microvessel lumen. 
CD68
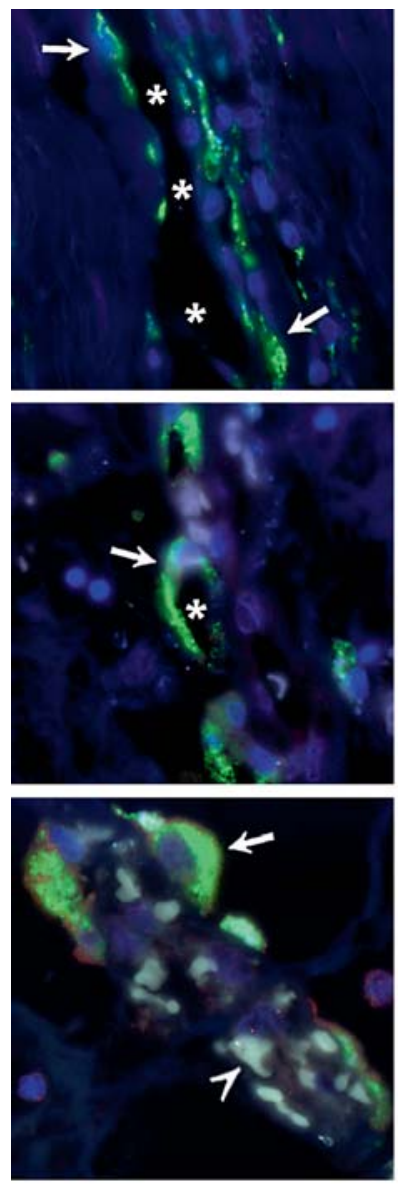
(please note: colours are shown in the online version only). a Longitudinal axis of a microvascular channel (asterisks) in diseased vessel adventitia showing costaining of CD68 (green) and Tie-2 (red). The merged image shows combined CD68 and Tie-2 staining (yellow). b Transverse section through multiple microvascular channels in diseased artery adventitia showing similar CD68/Tie-2 costaining. c Erythrocyte (white; open arrowhead)filled channel in longitudinal orientation within the adventitia of atherosclerotic vessel showing lining cells co-immunolabelling for CD68 and Tie-2. d, e Mouse (MIgG) and rabbit IgG (RIgG) control antibody labelling showing lack of immunoreactivity. f Double immunolabelling (merged-yellow) of CD68 (green) and Tie2 (red) in cells lining the endoluminal surface of atherosclerotic vessel. In each panel, arrows indicate cells that label positive for CD68 and Tie-2 singly and combined.

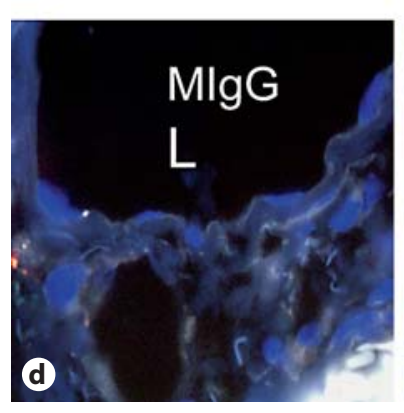

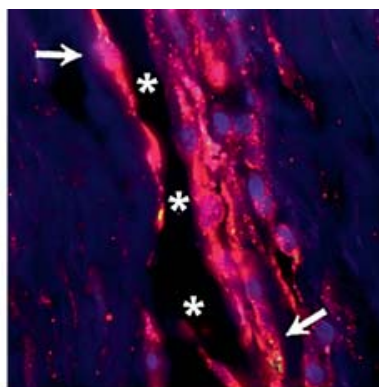

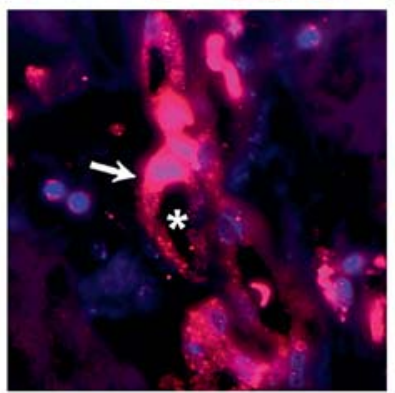

CD68/Tie-2 (merged)
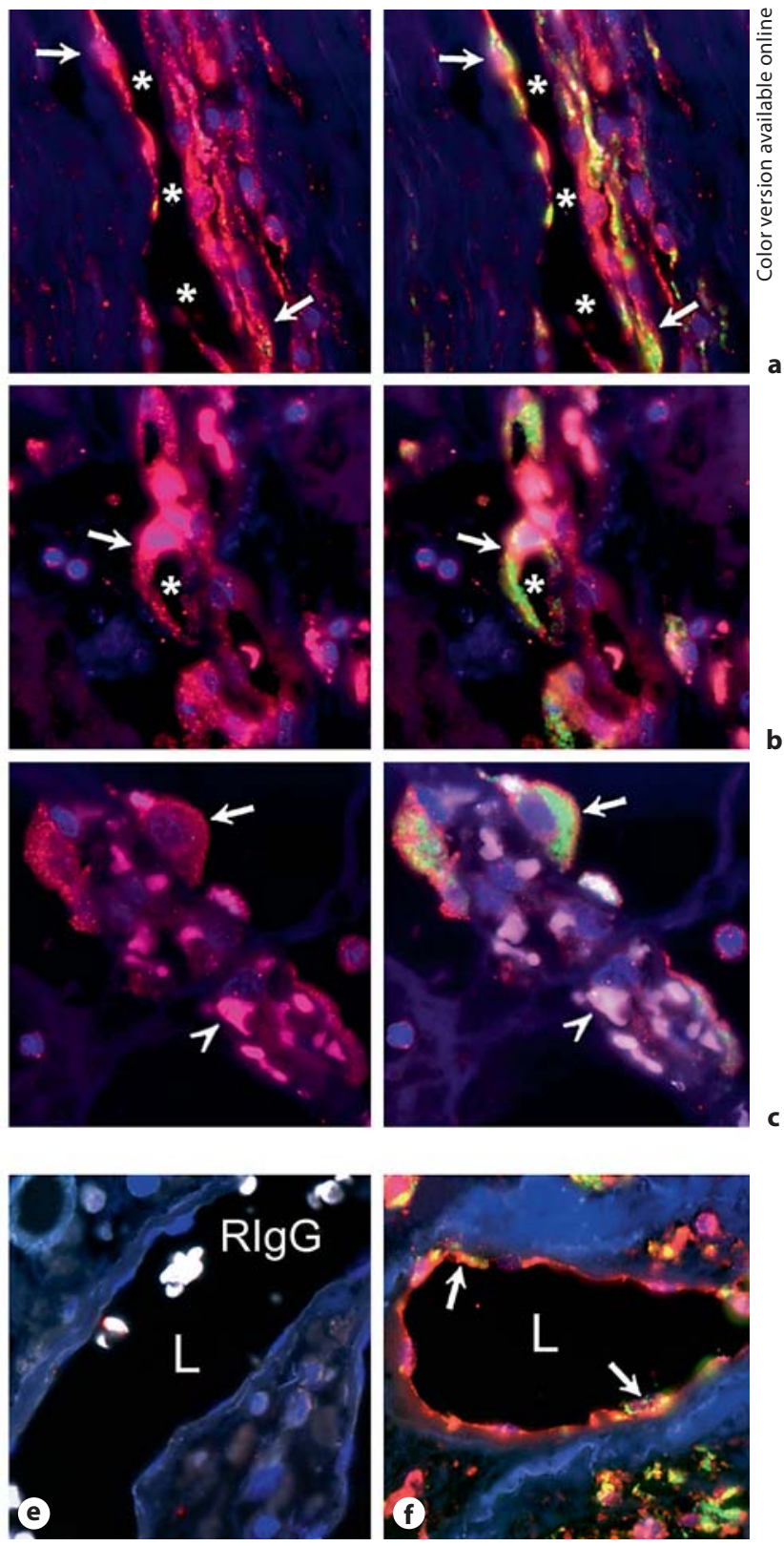

and Tie-2, and Flk-1 (VEGF-R2) were observed throughout several passages signifying EOC retained an endothelial-like phenotype. These data support several previous studies suggesting monocyte differentiation into endothelial-like cells in vitro $[2,24-26]$. In a rabbit ischaemic model, monocyte depletion impaired neovascularisation capacity of arteriogenic factors, such as placental growth factor, which interacts with the VEGF-R1 found on monocytes [27]. Furthermore, monocytes have been shown to incorporate into endothelium of mouse blood vessels (with co-administration of CD34+ cells) in a model of hind limb ischaemia [28].

Recently, human studies by Yoder et al. [29] defined two major groups of outgrowth cells from blood that are, on occasions, classified singly as EPC because of their expression of endothelial antigens; CFU-EC (EC colony forming units) which appeared to be of monocyte/macrophage origin (CD45+, CD14+ and no clonal expansion ability) and ECFC (endothelial colony-forming cells) which lacked myeloid markers and formed blood vessels 
Fig. 6. FISH for Y chromosome indicated that CD68/Tie-2 double-positive cells were of recipient in origin. [Online version: red $=$ CD68 and X chromosome (arrowhead); green $=$ Tie-2 and $\mathrm{Y}$ chromosome (open arrowhead); blue = DAPI-stained nuclei; yellow $=$ merged red $($ CD68) and green (Tie-2)]. The recipient-derived male cells are diploid as indicated by two sex chromosomes (arrow) and show no evidence of cell fusion. $\mathrm{L}=$ Lumen.
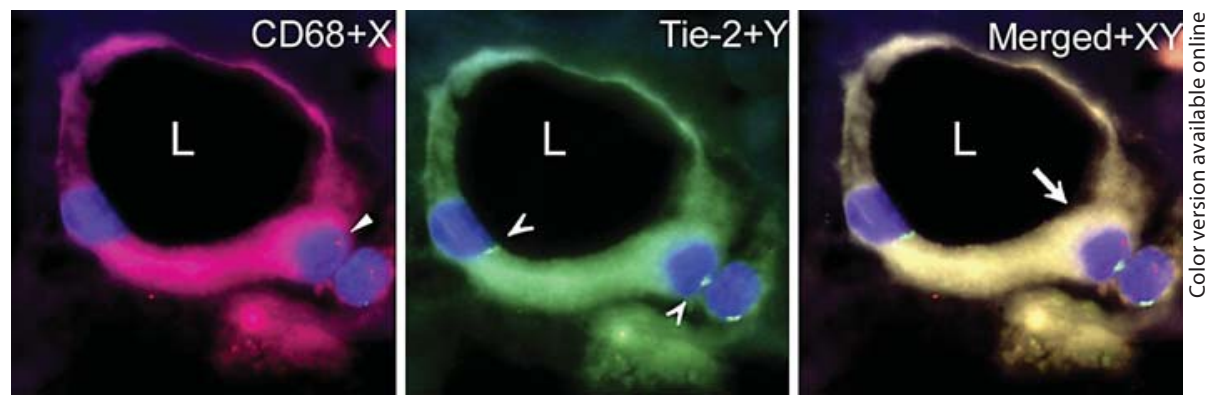

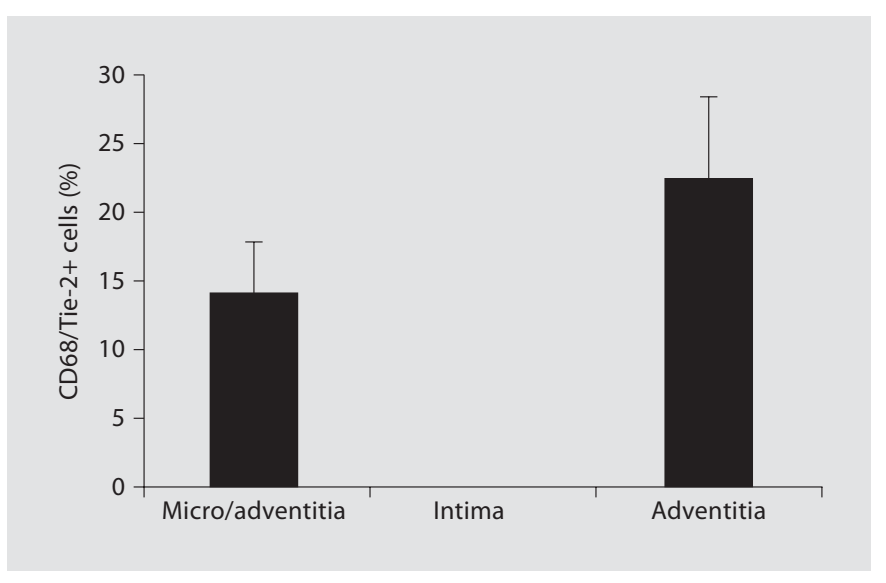

Fig. 7. Histograms showing the percentage of CD68/Tie-2 receptor double-positive stained cells (of total CD68+ cells) in adventitial microvasculature (Micro/adventitia), intima and adventitial loose connective tissue (adventitia) of diseased coronary arteries.

and could be clonally expanded. Although we agree that CFU-EC and ECFC are distinct, in contrast to the CFUEC and ECFC definition of Yoder et al. [29], the EOC in our study possessed both the ability to form secondary, tertiary (plus) colonies and expressed myeloid markers CD14 (in the early primary outgrowth) and CD68, and Mac-1 markers through extended tertiary culture. Our EOC preparation was similar to that described by Yoder et al. [30] and the cells are likely to be ECFC, but our data indicate some linkage to a myeloid lineage phenotype. Possibly the myeloid markers used in their study (CD14 and pan-leukocyte marker CD45) were already downregulated prior to analysis [31]. Prolonged cell culture in an environment not biased towards monocyte/macrophage differentiation may contribute to abrogation of CD14 expression. Moreover, the myeloid/EOC associa- tion seems to be supported by our examination of arterial specimens of sex-mismatched transplants.

To date, human data illustrating myeloid differentiation into endothelial-like cells in vivo or integration of myeloid cells into neovessels in diseased human arteries are limited. In this study, we show that cells of recipient origin expressing myeloid markers can be found lining donor cardiac transplant vessels extending the support for the concept that myeloid cells (or portion of the myeloid pool) may be the source of EC in neovascularisation. Cell fusion as a possible explanation of double labelling of myeloid and endothelial markers was excluded with chromosomal ploidy analysis and three-dimensional confocal microscopy used in this study.

Our data are also consistent with results from experiments in which targeted inhibition of plaque neovascularisation reduced macrophage accumulation and plaque progression in a murine model of atherosclerosis [31]. Possibly, myeloid cells in the circulation are highly plastic and are a ready source (or temporary substitute) for cells that are injured or need replenishment. As neovascularisation and monocytic cell infiltrates may be closely associated in atherosclerosis, the implication of a readily available pool of vascular progenitors in the circulation is great both in terms of basic and translational research. Targeting this myeloid differentiation pathway may allow modulation of arterial vasculogenesis.

\section{Acknowledgements}

This work was supported in part by grants from the National Institutes of Health (HL66958-NMC) and the Science Foundation Ireland (PI grant-NMC). 


\section{References}

1 Asahara T, Murohara T, Sullivan A, Silver M, Van der Zee R, Witzenbichler B, Schatteman $\mathrm{G}$, Isner J: Isolation of putative progenitor endothelial cells for angiogenesis. Science 1997;275:964-967.

2 Rohde E, Malischnik C, Thaler D, Maierhofer T, Linkesch W, Lanzer G, Guelly C, Strunk D: Blood monocytes mimic endothelial progenitor cells. Stem Cells 2006;24:357367.

- 3 Fan C, Li Y, Gao P, Liu J, Zhang X, Zhu D: Differentiation of endothelial progenitor cells from human umbilical cord blood CD34+ cells in vitro. Acta Pharmacol Sin 2003:24:212-218.

-4 Fujiyama S, Amano K, Uehira K, Yoshida M, Nishiwaki Y, Nozawa Y, Jin D, Takai S, Miyazaki M, Egashira K, Imada T, Iwasaka T, Matsubara H: Bone marrow monocyte lineage cells adhere on injured endothelium in a monocyte chemoattractant protein-1-dependent manner and accelerate reendothelialization as endothelial progenitor cells. Circ Res 2003;93:980-989.

5 Reyes M, Dudek A, Jahagirda B, Koodie L, Marker P, Verfaillie C: Origin of endothelial progenitors in human postnatal bone marrow. J Clin Invest 2002;109:337-346.

-6 Sainz J, Al Haj Zen A, Caligiuri G, Demerens C, Urbain D, Lemitre M, Lafont A: Isolation of 'side population' progenitor cells from healthy arteries of adult mice. Arterioscler Thromb Vasc Biol 2006;26:281-286.

-7 Zengin E, Chalajour F, Gehling UM, Ito WD, Treede H, Lauke H, Weil J, Reichenspurner H, Kilic N, Ergun S: Vascular wall resident progenitor cells: a source for postnatal vasculogenesis. Development 2006;133:15431551 .

-8 Urbich C, Heeschen C, Aicher A, Dernbach E, Yeiher A, Dimmerler S: Relevance of monocytic features for neovascularization capacity of circulating endothelial progenitor cells. Circulation 2006;108:2511-2516.

-9 De Palma M, Venneri M, Galli R, Sergi L, Politi L, Sampaolesi M, Naldini L: Tie2 identifies a hematopoietic lineage of proangiogenic monocytes required for tumor vessel formation and a mesenchymal population of pericyte progenitors. Cancer Cell 2005;8: 211-226.

10 Harrison JK, Jiang Y, Chen S, Xia Y, Maciejewski D, McNamara RK, Streit WJ, Salafranca MN, Adhikari S, Thompson DA, Botti P, Bacon KB, Feng L: Role for neuronally derived fractalkine in mediating interactions between neurons and CX3CR1-expressing microglia. Proc Natl Acad Sci USA 1998;95:10896-10901.
11 Fernandez PB, Lucibello F, Zuzarte M, Lutjens P, Muller R, Havemann K: Dendritic cells derived from peripheral monocytes express endothelial markers and in the presence of angiogenic growth factors differentiate into endothelial-like cells. Eur J Cell Biol 2001;80:99-110.

12 Caplice N, Bunch T, Stalboerger P, Wang S, Simper D, Miller D, Russell S, Litzow M, Edwards W: Smooth muscle cells in human coronary atherosclerosis can originate from cells administered at marrow transplantation. Proc Natl Acad Sci USA 2003;100: 4754-4759.

13 Loomans CJM, Wan H, de Crom R, van Haperen R, de Boer HC, Leenen PJM, Drexhage HA, Rabelink TJ, van Zonneveld AJ, Staal FJT: Angiogenic murine endothelial progenitor cells are derived from a myeloid bone marrow fraction and can be identified by endothelial NO synthase expression. Arterioscler Thromb Vasc Biol 2006;26:1760-1767.

14 Metharom P, Liu C, Wang S, Stalboerger P, Chen G, Doyle B, Ikeda Y, Caplice NM: Myeloid lineage of high proliferative potential human smooth muscle outgrowth cells circulating in blood and vasculogenic smooth muscle-like cells in vivo. Atherosclerosis 2008;198:29-38.

15 Simper D, Stalboerger P, Panetta C, Wang S, Caplice N: Smooth muscle progenitor cells in human blood. Circulation 2002;106:11991204.

16 Walter D, Haendeler J, Reinhold J, Rochwalsky U, Seeger F, Honold J, Hoffmann J, Urbich C, Lehmann R, Arenzana-Seisdesdos F, Aicher A, Heeschen C, Fichtlscherer S, Zeiher A, Dimmeler S: Impaired CXCR4 signaling contributes to the reduced neovascularization capacity of endothelial progenitor cells from patients with coronary artery disease. Circ Res 2005;97:1142-1151.

17 Ikpeazu C, Davidson M, Halteman D, Browning P, Brandt S: Donor origin of circulating endothelial progenitors after allogeneic bone marrow transplantation. Biol Blood Marrow Transplant 2000;6:301-306.

18 Asahara T, Masuda H, Takahashi T, Kalka C, gner $M$ Isner J: Bone marrow origin of endothelial progenitor cells responsible for postnatal vasculogenesis in physiological and pathological neovascularization. Circ Res 1999;85: 221-228.

19 George J, Afek A, Abashidze A, Shmilovich H, Deutsch V, Kopolovich J, Miller H, Keren G: Transfer of endothelial progenitor and bone marrow cells influences atherosclerotic plaque size and composition in apolipoprotein E knockout mice. Arterioscler Thromb Vasc Biol 2005;25:2636-2641.

20 Eizawa T, Ikeda U, Murakami Y, Matsui K, Yoshioka T, Takahashi M, Muroi K, Shimada $\mathrm{K}$ : Decrease in circulating endothelial progenitor cells in patients with stable coronary artery disease. Heart 2004;90:685-686.
21 George J, Goldstein E, Abashidze S, Deutsch V, Shmilovich H, Finkelstein A, Herz I, Miller H, Keren G: Circulating endothelial progenitor cells in patients with unstable angina: association with systemic inflammation. Eur Heart J 2004;25:1003-1008.

$>22$ George J, Goldstein E, Abashidze A, Deutsch V, Finkelstein A, Michowitz Y, Miller H, Keren G: Number and adhesive properties of circulating endothelial progenitor cells in patients with in-stent restenosis. Arterioscler Thromb Vasc Biol 2003;23:e57-e60.

23 Tao J, Wang Y, Yang Z, Tu C, Xu MG, Wang JM: Circulating endothelial progenitor cell deficiency contributes to impaired arterial elasticity in persons of advancing age. J Hum Hypertens 2006;20:490-495.

24 Lin Y, Weisdorf D, Solovey A, Hebbek R: Origins of circulating endothelial cells and endothelial outgrowth from blood. J Clin Invest 2000;105:71-77.

25 Anghelina M, Krishnan P, Moldovan L, Moldovan NI: Monocytes and macrophages form branched cell columns in Matrigel: implications for a role in neovascularization. Stem Cells Dev 2004;13:665-676.

26 Havemann K, Pujol B, Adamkiewicz J: In vitro transformation of monocytes and dendritic cells into endothelial like cells. Adv Exp Med Biol 2003;522:47-57.

$>27$ Pipp F, Heil M, Issbrucker K, Ziegelhoeffer T, Martin S, van den Heuvel J, Weich H, Fernandez B, Golomb G, Carmeliet P, Schaper W, Clauss M: VEGFR-1-selective VEGF homologue PlGF is arteriogenic: evidence for a monocyte-mediated mechanism. Circ Res 2003;92:378-385.

28 Harraz M, Jiao C, Hanlon HD, Hartley RS, Schatteman GC: CD34- blood-derived human endothelial cell progenitors. Stem Cells 2001;19:304-312.

-29 Yoder MC, Mead LE, Prater D, Krier TR, Mroueh KN, Li F, Krasich R, Temm CJ, Prchal JT, Ingram DA: Redefining endothelial progenitor cells via clonal analysis and hematopoietic stem/progenitor cell principals. Blood 2007;109:1801-1809.

30 Ingram DA, Mead LE, Tanaka H, Meade V, Fenoglio A, Mortell K, Pollok K, Ferkowicz MJ, Gilley D, Yoder MC: Identification of a novel hierarchy of endothelial progenitor cells using human peripheral and umbilical cord blood. Blood 2004;104:2752-2760.

-31 Moulton K, Heller E, Knoerding M, Lynn E, Palinski W, Folkman J: Inhibition of plaque neovascularization reduces macrophage accumulation and progression of advanced atherosclerosis. Proc Natl Acad Sci USA 2003;100:4736-4741 